\title{
Seismic inversion and its contribution for detailed salt section characterization: an application in the Santos Basin, Brazilian offshore
}

Thiago Yamamoto (Petrobras), Alexandre Maul (Petrobras) and Wagner Lupinacci (GIECAR-UFF)

Copyright 2021, SBGf - Sociedade Brasileira de Geofísica.

This paper was prepared for presentation during the $17^{\text {th }}$ International Congress of the Brazilian Geophysical Society held in Rio de Janeiro, Brazil, $16-19$ August 2021.

Contents of this paper were reviewed by the Technical Committee of the $17^{\text {th }}$ International Congress of the Brazilian Geophysical Society and do not necessarily represent any position of the SBGf, its officers or members. Electronic reproduction or storage of any part of this paper for commercial purposes without the written consent of the Brazilian Geophysical Society is prohibited.

\begin{abstract}
Since the discovery of the Pre-Salt carbonate reservoirs in the Santos Basin, Brazilian offshore, a new hydrocarbon frontier emerges facing new challenges for Exploration and Production (E\&P) industry. The tremendous amount of oil \& gas in these reservoirs, currently the main portion of the Brazilian reserves, are below a saline evaporitic section that normally presents thicknesses greater than $2 \mathrm{~km}$. This evaporitic section presents high structural complexity, thickness variation and mineral variability. The geological record of the subsurface data reveals that this salt section is mainly composed by halite, anhydrite, carnallite, tachyhydrite and sylvite. Mineral variation is a key aspect when dealing with these portions, especially in terms of seismic interpretation and well log evaluation. The combination of these three main aspects: thickness range, structural complexities and mineral variation, demands a detailed study for the characterization of the evaporitic section. For offshore portions, it is common to have sparse wells information to calibrate the built models, which causes problems regarding the reality of the built models. Model-based seismic inversion helps to overcome situations like these, where there are sparse wells it is necessary to carry out a good geological evaluation based on seismic information to cover the entire project area. In this work, we present an adaptation of a model-based seismic inversion methodology, used for reservoir characterization, to model the distribution of salt minerals spatially in the Santos Basin. We summarize the main petroelastic properties found in the analysis of the well logs and fill the well-log gaps, ensuring a reliable statistical assay of the mineral occurrence representation. Later, we present a built 3D petroelastic model based on information from well and seismic data. From this methodology, we have generated models of elastic properties for the analysis of uncertainties in the depth positioning, for the initial velocity model in the update process during the seismic migration task, geomechanical simulation models and safety in well-drilling stages. Therefore, the methodology has been used in Pre-Salt projects in the Santos Basin, assisting in better decision-making in all related phases: exploration, appraisal, development and production.
\end{abstract}

